\title{
The use of Temperature and Relative Humidity Sensors to Estimate the Final Moisture Content of the Drying Process
}

\author{
Surachai Hemhirun \\ Department of Mechanical Engineering \\ Srinakharinwirot University (SWU) \\ Nakhon Nayok, Thailand
}

\author{
Pracha Bunyawanichakul \\ Department of Mechanical Engineering \\ Srinakharinwirot University (SWU) \\ Nakhon Nayok, Thailand
}

\begin{abstract}
The estimation of the paddy moisture content during the drying process was important to retain the moisture level properly for trade $(15 \% \mathrm{wb})$ or storage. In general, the agriculturists estimated moisture content by using a moisture detector (Riceter F512). This allowed the user to determine the moisture level, once the drying process was completed. The objective of this paper was to estimate the final moisture content (FMC) of the paddy drying process by using the mass balance method. The temperature and relative humidity sensor were installed at two locations, one for surrounding air (DHT22sensor) and another one to exhaust air (EE31-sensor) of the dryer in order to read and record data values. Arduino microcontroller was used as the main processor that receives the property of air from a DHT22, EE31 sensor. After that, the processor would calculate the humidity ratio of air and send the signal output to indicate the moisture level of the paddy that was reduced. Besides, the moisture reduction was compared with the traditional method by using a moisture detector. The drying condition used in this study was set: paddy initial moisture content (IMC) range $20-21 \% \mathrm{wb}$, rotary valve speed of $2 \mathrm{rpm}$ (equivalent to $60 \mathrm{~kg} / \mathrm{h}$ ), the average hot-air temperature of 130 ${ }^{\circ} \mathrm{C}$, hot-air velocities of $2 \mathrm{~m} / \mathrm{s}$ and the average eccentric speed of 110 RPM. The results showed that the system could estimate and display moisture content of the paddy that was a reduction from IMC to FMC and the average error values of 4.3 percent when compared with a moisture detector.
\end{abstract}

Keywords-Temperature sensor, humidity sensor, Arduino, Final moisture content

\section{INTRODUCTION}

Paddy rice is an important economic crop in Thailand [1]. Each year, the average output of Thai paddy rice runs at 31-33 million metric tons [2], and the moisture content is generally stated on a wet basis (wb). After the harvest, the paddy would contain high moisture content, depending on the season and harvest time that it has to be dehydrated to destroy bacteria and prevent grain deterioration [3]. Generally, the fresh paddy is sold to the rice mill industries; a selling price depends on the moisture content or initial moisture content (IMC) of the paddy, which can be measured by a moisture detector (Riceter F512)

For the paddy that contains over $15 \%$ wb moisture content, the selling price would be reduced. On the contrary, the weight would be reduced according to the regulation of the department of internal trade (DIT) of Thailand as showed in Table I.

\begin{tabular}{|c|c|c|c|c|}
\hline TABLE III. & \multicolumn{4}{|c|}{$\begin{array}{l}\text { SELLING PRICE AT VARIOUS MOISTURE LEVELS } \\
\text { (INFORMATION YEAR 2013/14) }\end{array}$} \\
\hline \multirow{2}{*}{$\begin{array}{l}\text { IMC } \\
(\% \text { wb) }\end{array}$} & \multicolumn{2}{|c|}{ Weight (kg) } & \multirow{2}{*}{$\begin{array}{l}\text { Selling price } \\
\text { (THB/ton) }\end{array}$} & \multirow{2}{*}{$\begin{array}{l}\text { Price was reduced } \\
\text { (THB/ton) }\end{array}$} \\
\hline & net & lose & & \\
\hline Not exceed 15 & 1,000 & - & 15,000 & - \\
\hline 16 & 985 & 15 & 14,775 & 225 \\
\hline 17 & 970 & 30 & 14,550 & 450 \\
\hline 18 & 955 & 45 & 14,325 & 675 \\
\hline 19 & 940 & 60 & 14,100 & 900 \\
\hline 20 & 925 & 75 & 13,875 & 1,125 \\
\hline 21 & 910 & 90 & 13,650 & 1.350 \\
\hline 22 & 895 & 105 & 13,425 & 1,575 \\
\hline 23 & 880 & 120 & 13,200 & 1,800 \\
\hline
\end{tabular}

When the high moisture paddy is sold, the selling price is reduced with the increased moisture content that affects the economic return [4]. In general, the agriculturists still use nets for sun-drying in order to reduce moisture content. However, if there is no sunlight or during the rainy season, sun drying would not be possible. A suitable way to reduce moisture content can be done by a machine called a dryer. Typically, the dryer is a tool to remove water contained in the paddy grain by using heated air flow passed through the paddy layer which causes heat and mass transfer between paddy grain and hot air that should be dried by $15 \%$ wb moisture content to trade at the rice mills (without reducing the trade price due to moisture content) or the appropriate level 14-15\%wb, then it will be ready for exports, preservation, and storage [5]. The moisture is measured during the drying process and finishes the drying process. Mostly, the samples are taken by the user from the drying process, measured by a moisture detector which is sufficiently precise according to the use of the moisture meter on the post-harvest, which has been studied by MA Hossain et al. [6]. The disadvantage of this method is that the user must take out the sample from the drying process, recognize the moisture after the drying process has finished.

Therefore, the moisture content reduction during the drying process was displayed to the user, which is very important. (Without taking out the sample from the drying process)

The first objective of this study was to apply the temperature and relative humidity sensors to read and record the data values. 
The second objective was to calculate the essential values and estimated FMC by using a mass balance method after that compare the estimated FMC with a moisture detector.

\section{MATERIALS AND METHODS}

\section{A. Materials}

The experiment selected local fresh rice paddy in the central region of Thailand, cultivar RD31 (Pathum Thani 1) [7]. Then, the paddy was packed in a plastic bag to maintain moisture by keeping it in the refrigerator at $4{ }^{\circ} \mathrm{C}$, Before the experiment, the fresh paddy was taken out the refrigerator which was left at the ambient air to grain thermal balance for 20-minutes [8].

\section{B. Cross-flow paddy dryer}

The dryer was a prototype for a small community that was created in the department of mechanical engineering at SWU. Fig. 1. (a), represents a schematic diagram of the dryer and the location of the main equipment used in this experiment.

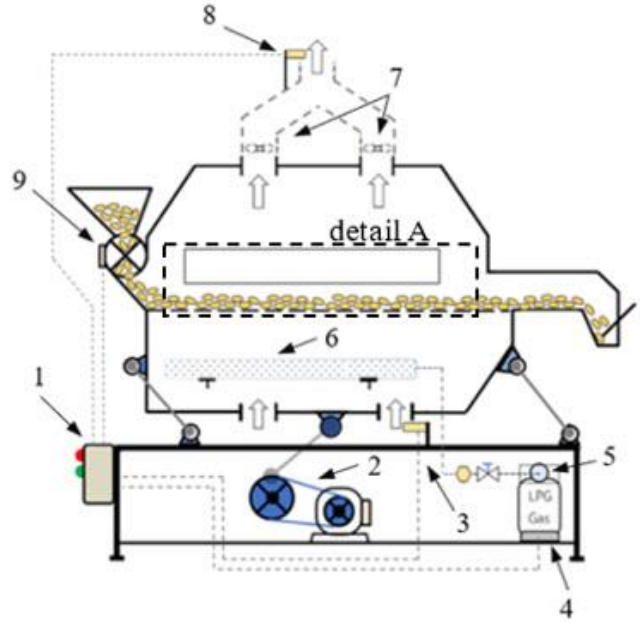

(a)

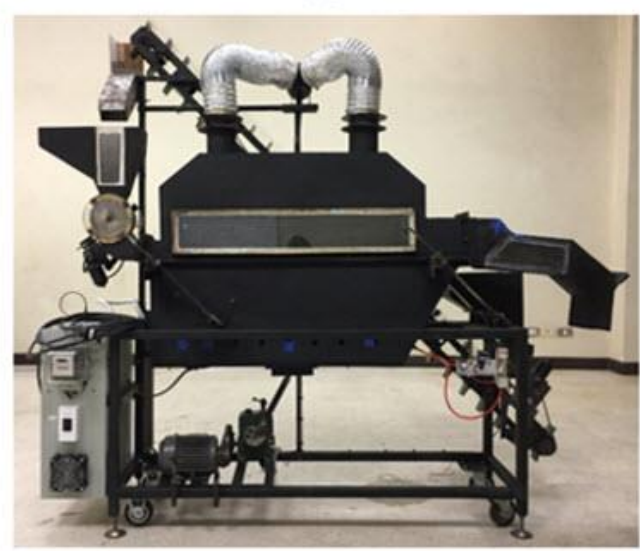

(b)

Fig. 1. (a) A schematic diagram of the dryer consists of the unit as follows, 1) control panel; 2) motor driver eccentric set; 3) temperature \& humidity sensor (air inlet: DHT22); 4) digital scales; 5) cooking gas cylinder; 6) infrared gas burner; 7) axial fan; 8) temperature \& humidity sensor (air outlet: EE31); 9) rotary valve feeder; 10) hot air chamber and (b) Real image of a cross-flow dryer

The operation of the dryer started from, feeding the paddy into the drying chamber by rotary valve feeder, and then the paddy layer moves from the left to the right side on the distributor plate, pass through the drying chamber by motor driver eccentric set. The size of the dryer is that of a drying chamber (wide $\mathrm{x}$ long) of $0.15-\mathrm{m} \times 1-\mathrm{m}$ which contained an air distributor plate made of stainless-steel with $30 \%$ the open area, hole $0.003-\mathrm{m}$ diameter, and $0.002-\mathrm{m}$ the thickness. Meanwhile, the hot air from the infrared gas burner is produced from the infrared gas burner that flows from air inlet at a downside to the top side of the hot air chamber that some researchers call "a Must Flow Dryer" as [9], [10] and a real image of a cross-flow dryer as shown in Fig.1. (b). In general, the direction of material moved perpendicularly or crossed with the hot air flow which this characteristic is referred to a cross-flow dryer [11], [12].

\section{Experimental set-up and drying process}

In a cross-flow dryer experiment, the process started from a dryer setup. Fig. 2 shows the flow chart of the experimental procedure of the paddy drying process.

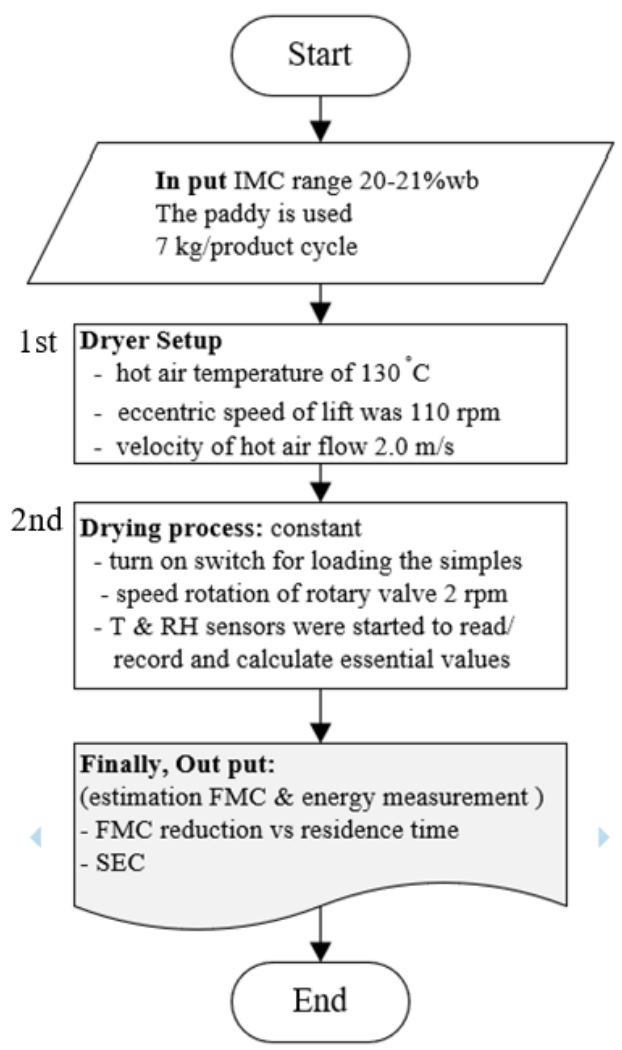

Fig. 2. Flow chart of an experimental procedure

Firstly, the moisture of the fresh paddy which can be measured by a moisture detector "KETT" (Riceter F512) model: compression type with an accuracy of 0.5 percent, if it contained the IMC range of $20-21 \% \mathrm{wb}$ and each experiment had been performed in three replications. parameter as follows (the hot air temperature of $130^{\circ} \mathrm{C}$, the eccentric speed of lift of $110 \mathrm{rev} / \mathrm{min}$, and the velocity of hot airflow of $2 \mathrm{~m} / \mathrm{s}$ which was measured by an EXTECH Instruments: model AN100 thermo-anemometer, Thailand with air velocity $\pm 3 \% \mathrm{~m} / \mathrm{s}$ basic accuracy. The temperature inside the hot air chamber is measured by a thermocouple type $\mathrm{K}$, with 5 -point installations along with a chamber as shown in detail A, a thermocouple connects to a data logger with an accuracy of $\pm 1{ }^{\circ} \mathrm{C}$. Before drying operation, the hot air flows through the air distributor 
plate from the hot air chamber to the drying chamber as shown in Fig. 3. After that, the parameter was adjusted for a while to establish a steady-state condition.

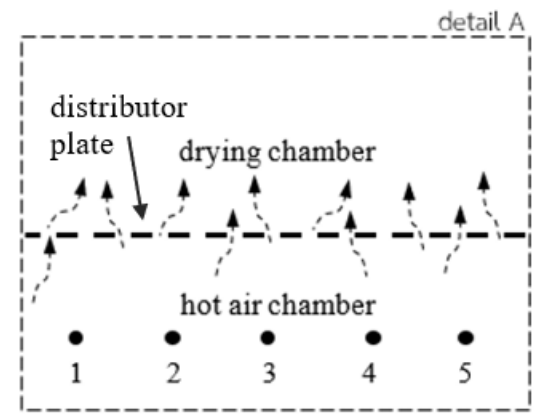

Fig. 3. The position of temperature measuring points

Secondly, the user turns on the switch to feed the paddy into the drying chamber at speed rotation of rotary valve 2 rev/min (approximate capacity: $60 \mathrm{~kg} / \mathrm{h}$ ). Simultaneously, the temperature $(\mathrm{T})$ and relative humidity $(\mathrm{RH})$ sensors at the two locations had started to read and record that the signal data was sent to a microcontroller for calculating essential values for evaluating the FMC. After $7 \mathrm{~kg}$ paddy was completely fed into the drying chamber, all paddies were moved to the outlet of the dryer.

Finally, all paddies would be weighed and measured to find that the weight was reduced, and the final moisture content (FMC) was reported (one cycle product). After that, the FMC value from the estimated program was compared with FMC from a moisture detector. For moisture content measurement of the paddy grain before and after drying, moisture content of five randomly chose the paddy grain at the entrance (inlet) and exit (outlet) of the dryer.

The experiment was conducted repeatedly by adjusting the velocity of hot airflow of $2.5 \mathrm{~m} / \mathrm{s}$ and $3.0 \mathrm{~m} / \mathrm{s}$ respectively.

\section{Temperature and relltive humidity sensors}

The ambient air temperature (T) and humidity were measured (RH) by using DHT22 digital temperature and humidity sensors which the researchers applied [13], [14] to the data logger equipment. The $\mathrm{T}$ and $\mathrm{RH}$ of the hot air after pass drying chamber of the cross-flow paddy dryer that was measured by E+E ELEKTRONIC: series EE31 humidity and temperature transmitter. Both sensors were connected and communicated to Arduino Uno (a microcontroller unit (MCU) based on the ATmega328P 8 bit), it has a 6 analog input pin and a 14 digital I/O pin. DHT22 and EE31 sensors are connected to the digital pins and the analog pin respectively as shown in Fig. 4.

Two sensors were calibrated. The temperature $(\mathrm{T})$ and relative humidity $(\mathrm{RH})$ of DHT22 sensor were calibrated by a hot-wire air velocity meter "TENMARS" (TM-4001) in T and $\mathrm{RH}$ function, for $\mathrm{T}$ an accuracy of \pm 1 percent and $\mathrm{RH}$ an accuracy of \pm 5 percent. And the EE31 sensor was calibrated by the indoor air quality monitor "Q-TRAK ${ }^{\mathrm{TM} \text { " }}$ model: 7575

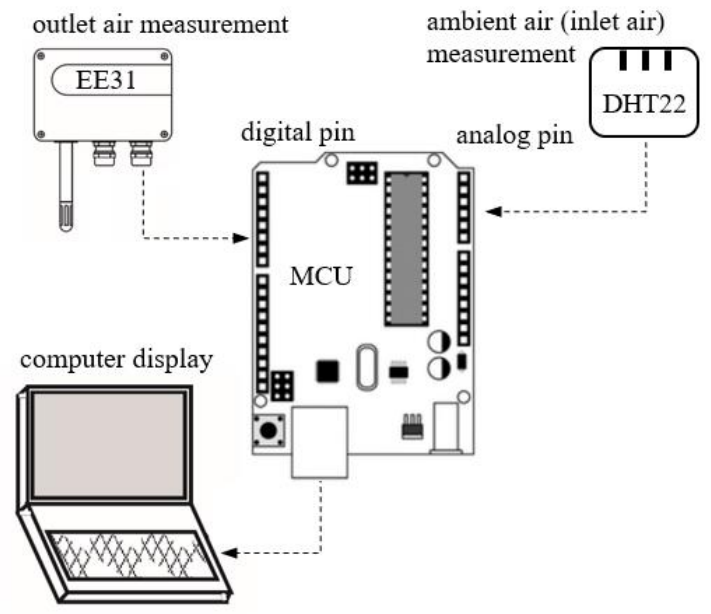

Fig. 4. The connection of the sensors to MCU

(792 thermocouple probes temperature and 982 IAQ Probes model temperature and humidity). Temperature accuracy of \pm 1.1 percent and RH an accuracy of \pm 3 percent. Both sensors' specifications are shown in Table II.

TABLE IV. SPECIFICATION OF THE SENSORS

\begin{tabular}{|l|c|c|c|c|}
\hline \multirow{2}{*}{\multicolumn{1}{c}{ Title }} & \multicolumn{2}{|c|}{ DHT22 Sensor } & \multicolumn{2}{c|}{ EE31 Sensor } \\
\cline { 2 - 5 } & $\boldsymbol{T}\left({ }^{\circ} \boldsymbol{C}\right)$ & $\boldsymbol{R H}(\% \boldsymbol{R H})$ & $\boldsymbol{T}\left({ }^{\circ} \boldsymbol{C}\right)$ & $\boldsymbol{R H}(\% \boldsymbol{R H})$ \\
\hline sensing element & DS18B20 & $\begin{array}{c}\text { polymer } \\
\text { capacitor }\end{array}$ & Pt1000 & HC1000-400 \\
\hline operating range & $-40 \sim 80$ & $0-100$ & $-40 \sim 180$ & $0-100$ \\
\hline measuring range & $25-32$ & $20-80$ & $22-80$ & $10-95$ \\
\hline $\begin{array}{l}\text { accuracy } \\
\text { before calibrating }\end{array}$ & \pm 0.5 & \pm 5 & \pm 0.6 & \pm 2.3 \\
\hline $\begin{array}{l}\text { accuracy } \\
\text { after calibrating }\end{array}$ & \pm 1.0 & \pm 8 & \pm 2.0 & \pm 20 \\
\hline
\end{tabular}

\section{E. Mass balance method}

Drying is the process that removes water out from the grain paddy to a proper level for selling to the rice mills. The mass balance method has been developed based on the mass balance in moisture transfer as shown in Fig. 5. There are four statements as follow: state 1 the paddy is fed inlet to the drying chamber which contains high moisture (IMC), state 2 the paddy left out of the drying chamber which it was reduced moisture (FMC), the hot air at high temperature $\left(\mathrm{T}_{3},{ }^{\circ} \mathrm{C}\right)$ and low relative humidity $\left(\mathrm{RH}_{3}, \%\right)$ would be entered in state 3 and left out of the drying chamber at low temperature $\left(\mathrm{T}_{4},{ }^{\circ} \mathrm{C}\right)$ and high relative humidity $\left(\mathrm{RH}_{4}, \%\right)$ in state 4 . 


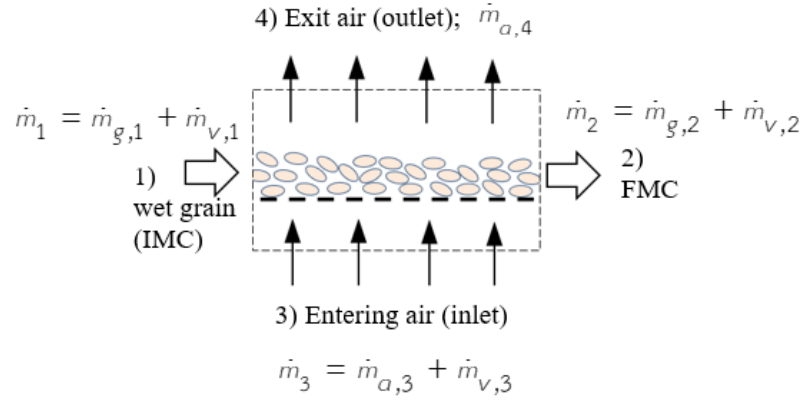

Fig. 5. Mass balance in the drying chamber

The mass balance method is divided into two-parts; one is balanced on the water as expressed in (1).

The mass balance on water $\left(\dot{m}_{v}\right)$ :

$$
\dot{m}_{v, 1}=\dot{m}_{v, 2}+\dot{m}_{v, 3}
$$

The mass balance of air $\left(\dot{m}_{a}\right)$ :

$$
\dot{m}_{a, 3}=\dot{m}_{a, 4}=\frac{A \times V}{v}
$$

Where; $\dot{m}_{v}$ is the mass flow rate of water of any phase in $\mathrm{kg} / \mathrm{s} . \dot{m}_{a}$ is the mass flow rate of dry air in $\mathrm{kg} / \mathrm{s}$. Subscripts numbers $1,2,3$, and 4 are state of the mass balance method.

The partial pressure of water vapor $\left(P_{v}\right)$ :

$$
P_{v}=P_{v s} \times\left[\frac{R H}{100}\right]
$$

Humidity ratio $(w)$ :

$$
w=\frac{\dot{m}_{v}}{\dot{m}_{a}}=\frac{0.622 P_{v}}{P-P_{v}}
$$

Where; $P$ is the partial pressure of water vapor in $\mathrm{Pa}$ and the subscript $v$ and $v s$ are at state vapor and vapor saturates respectively. $R H$ is the relative humidity in percentage (\%).

Therefore, the calculation amounts of water that must be removed from the grain paddy can be calculated by using the equation (5) as well as [15].

$$
m_{v, 4}=\left(w_{4}-w_{3}\right) \times \dot{m}_{a, 3} \times n
$$

Where; $m_{w, 4}$ is the amount of moisture removed (state 4) in $\mathrm{kg}, A$ is an area of outlet hot air duct in $\mathrm{m}^{2} . V$ is the velocity of hot air flow in $\mathrm{m} / \mathrm{s} . \quad v$ is a specific volume in $\mathrm{m}^{3} / \mathrm{kg}, n$ is the pickup factor according to [15] (in this paper using $n$ of 0.4 ) and $w$ is humidity ratio ( $\mathrm{kg}$ of water per $\mathrm{kg}$ of dry air), the subscript 3 and 4 are humidity ratio of ambient air inlet state and exit air outlet state respectively.

$$
F M C_{4}=\frac{m_{r, 1} I M C_{1}-100 m_{v, 4}}{m_{r, 1}-m_{v, 4}}
$$

Where; $F M C$ is the final moisture content in $\%$, wet basis (wb) at state 4, IMC is the initial moisture content in \%wb at state $3, m_{r}$ is the mass of incoming paddy grain dried in a one cycle product in $\mathrm{kg}$ and $m_{w}$ is the mass of water removed during each cycle product.

\section{RESULTS AND DISCUSSION}

\section{A. Temperature and relative humidity measurements}

As the experimental setup, the paddy drying process with a cross-flow dryer, after the parameter was adjusted for a while to establish a steady-state condition. Then the user turns on the switch to feed the paddy, the experiment was conducted repeatedly by adjusted the velocity of hot airflow of 2.0, 2.5 $\mathrm{m} / \mathrm{s}$, and $3.0 \mathrm{~m} / \mathrm{s}$ respectively. During the drying process, two sensors are used to read and record the temperature $(\mathrm{T})$ and relative humidity $(\mathrm{RH})$ values of the dryer, both sensors recorded measured values of $\mathrm{T}$ and $\mathrm{RH}$ at intervals of one minute throughout of the drying process, the temperature could read on the left axis and the right axis displaying the relative humidity.

Fig. 6 is a graphical representation of the measured values for the DHT22 sensor. The upper lines show the T of ambient air and the lower line shows the RH of ambient air that was consistent throughout the experiment. All of the conditioning experiment the $\mathrm{T}$ fluctuated between $27.6{ }^{\circ} \mathrm{C}, 30.4{ }^{\circ} \mathrm{C}$ while the RH fluctuated between $46.1 \%, 52.9 \%$ as shown in the DHT sensor column in Table III. Also, the T and RH were slightly increased due to the experiment that was conducted in a closed room.

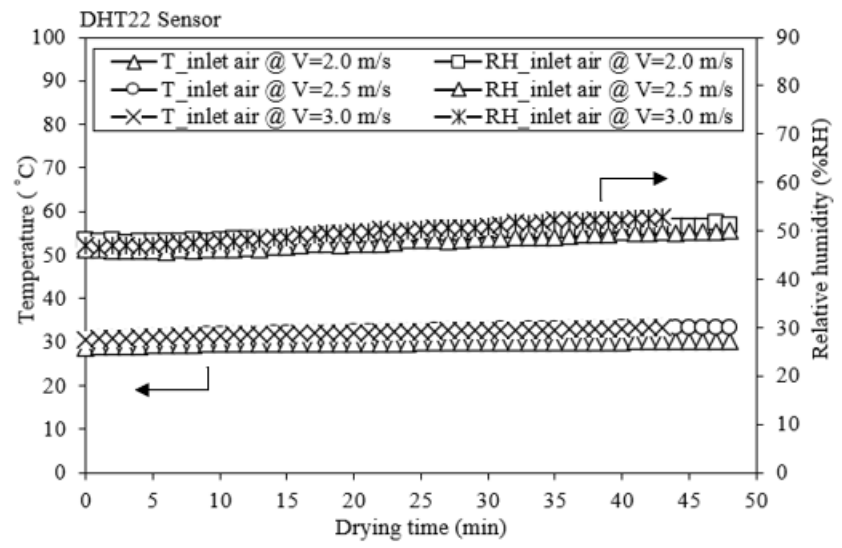

Fig. 6. Temperature and moisture versus drying time at a different velocity of hot air (DHT22 sensor)

Fig. 7(A-C) is a graphical representation of the measured value for the EE31 sensor. The trend of the temperature quickly decreased within ten minutes from the beginning, after that it was gradually increased, based on the hot air velocity that it was adjusted as previously mentioned. This also caused the temperature to decrease as follows, Fig. 7(A) from $69.3{ }^{\circ} \mathrm{C}$ to $48.4{ }^{\circ} \mathrm{C}$ at the hot air velocity of $2.0 \mathrm{~m} / \mathrm{s}$, fig. 7(B) from $57.5 .3{ }^{\circ} \mathrm{C}$ to $51.9{ }^{\circ} \mathrm{C}$ at the hot air velocity of $2.5 \mathrm{~m} / \mathrm{s}$ and fig. 7 (C) $69.6{ }^{\circ} \mathrm{C}$ to $57.2{ }^{\circ} \mathrm{C}$ at the hot air velocity of $3.0 \mathrm{~m} / \mathrm{s}$, respectively. On the other hand, the trend of the relative humidity quickly increased within ten minutes as well, after that; it gradually decreased based on the hot air velocity that was adjusted. This also caused the RH to increase as follows, Fig. 7(A) from $11.3 \%$ to $33.4 \%$ at the hot air velocity of 2.0 
$\mathrm{m} / \mathrm{s}$, fig.(B) from $16.1 \%$ to $33.4 \%$ at the hot air velocity of 2.5 $\mathrm{m} / \mathrm{s}$ and fig. $7(\mathrm{C}) 10.6 \%$ to $24.7 \%$ at the hot air velocity of 3.0 $\mathrm{m} / \mathrm{s}$, respectively.
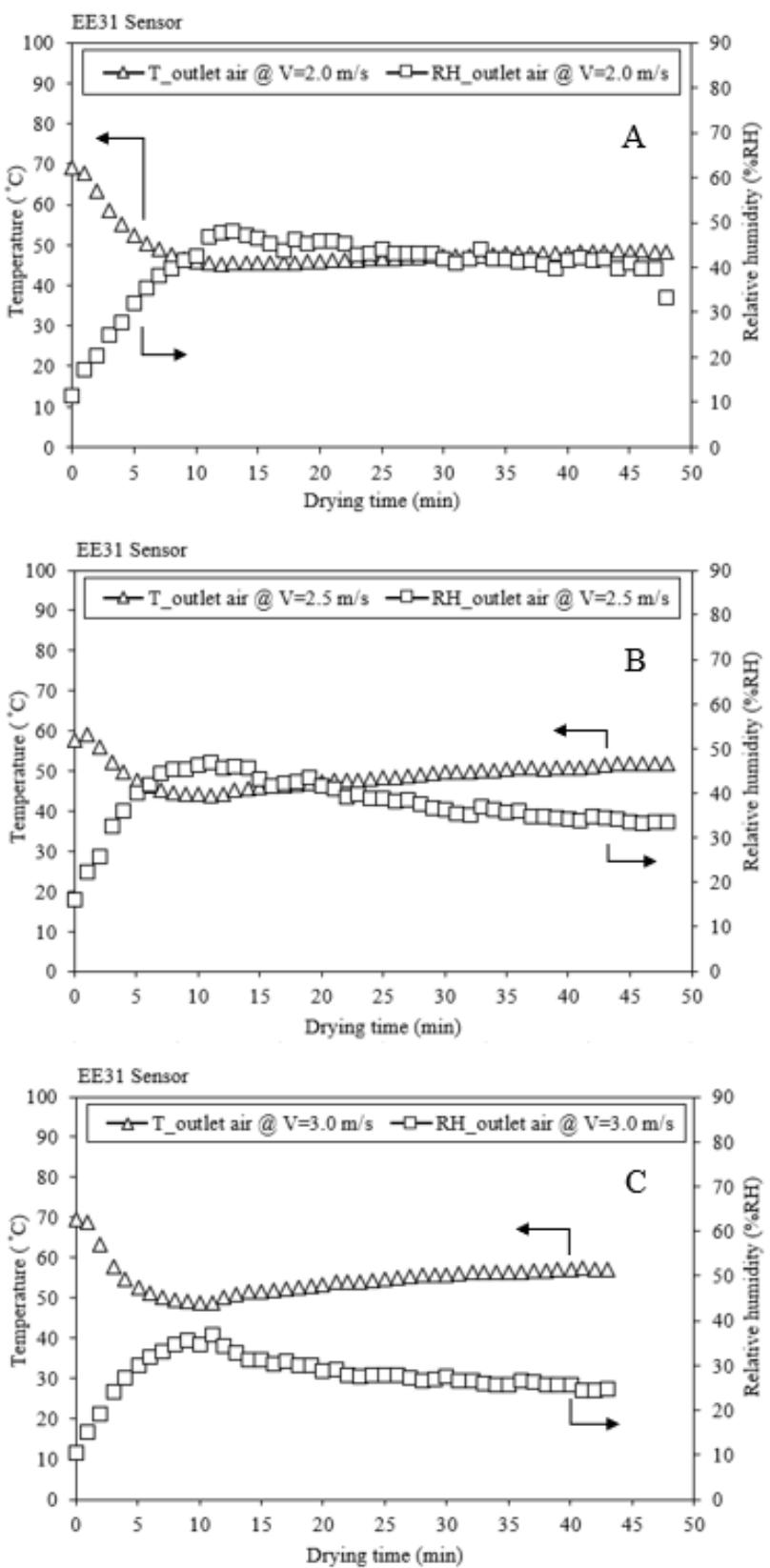

Fig. 7. Temperature and moisture versus drying time at a different velocity of hot air (EE31 sensor)

Also, the duration time for the drying process was approximately 43 minutes, for the velocity of hot air was set to $3.0 \mathrm{~m} / \mathrm{s}$ as shown in Fig.7(C). On the contrary, there was not a noticeable change in regards of the drying time, which still is 48 minutes, for the velocity of hot air was set to $2.0 \mathrm{~m} / \mathrm{s}$ and $2.5 \mathrm{~m} / \mathrm{s}$ respectively as shown in Fig.7 (A, B).
Moreover, the increase in the velocity of hot air through the drying chamber would cause the RH to increase. As the velocity of air increases, the mass flow rate would also increase as explained in (2). As a result, heat and mass transfer occurs, for the heat transfer side, the temperature of hot air at state 4 would gradually increase and mass transfer between the mass of hot air with the mass of water evaporated from the paddy grain as shown in Fig. 5. Which the mass of water evaporates from the paddy grain, in which it was absorb by the mass of hot air flows, therefore the mass of the paddy would be reduced. The effect of slightly decreased drying time because the mass was reduced which made the paddy move through the drying chamber faster.

However, at the beginning of the drying process, both sensors were sent the data values to MCU, which read and recorded the property of air as shown in DHT and EE31 sensor column in Table III

\section{B. Estimation of the final moisture content}

The estimation of the FMC of the paddy drying process by the mass balance method, there are three main steps as follows.

Firstly, the MCU has received the data values ( $\mathrm{T}$ and $\mathrm{RH}$ ) from the sensors as explained and previously mentioned, then these data are calculating the essential values such as the partial pressure of water and humidity ratio in the air at the state 3,4 and it was calculating, using (3), (4) respectively. The humidity ratio is the values to identify, the percentage of the ratio between the amounts of moisture or water vapor in the air holding with the amount of moisture in the air can hold. The moisture ratio was explained in the humidity ratio column in Table III.

Secondly, calculate the mass flow rate of the air at inlet and outlet was explained in (2). Then taken these value multiples with humidity ratio as (5), that would be able to estimate the mass of water removed out of the paddy as (1) to explain the whole paddy grain consist the amount of the dry paddy grain and the water inside the paddy.

Lastly, preparation of the data value from the drying condition and the experiment, such as the mass $\left(m_{r}\right)$ and the initial moisture content (IMC) of the paddy per one cycle product. Including, the mass of water removed $\left(m_{v}\right)$ as a previous step then replaced all of these data values in (6). The final moisture content $(F M C)$ in the paddy drying process was estimated, and was shown the FMC was reduced in the drying process in Fig. 8. The FMC has tended to reduce along with the drying time, and it could reduce the moisture of the paddy grain from IMC to FMC down from 20.7 to $16.3 \%$ wb at the velocity that was adjusted to $2.0 \mathrm{~m} / \mathrm{s}, 20.7$ to $14.8 \% \mathrm{wb}$ at the velocity that was adjusted to $2.5 \mathrm{~m} / \mathrm{s}$ and 20.6 to $13.7 \%$ wb respectively. In FMC column in Table III was shown the FMC every ten minutes from the beginning to finish the drying process. 
TABLE III. TEMPERATURE AND HUMIDITY MEASUREMENTS DATA FROM THE SENSORS

\begin{tabular}{|c|c|c|c|c|c|c|c|c|c|c|}
\hline \multirow{3}{*}{$\begin{array}{c}\text { Drying } \\
\text { condition } \\
(\mathrm{m} / \mathrm{s})\end{array}$} & \multirow{3}{*}{$\begin{array}{c}\text { Drying time } \\
(\min )\end{array}$} & \multirow{2}{*}{\multicolumn{2}{|c|}{ DHT22 sensor }} & \multirow{2}{*}{\multicolumn{2}{|c|}{ EE31 sensor }} & \multirow{2}{*}{\multicolumn{3}{|c|}{$\begin{array}{l}\text { Humidity ratio ( } \omega) \\
\text { (kg water/kg dry air) }\end{array}$}} & \multirow{3}{*}{$\begin{array}{l}\text { IMC } \\
(\% w b)\end{array}$} & \multirow{3}{*}{$\begin{array}{l}\text { FMC } \\
(\% w b)\end{array}$} \\
\hline & & & & & & & & & & \\
\hline & & $T_{3}\left({ }^{\circ} \mathrm{C}\right)$ & $\mathrm{RH}_{3}(\%)$ & $T_{4}\left({ }^{\circ} \mathrm{C}\right)$ & $\mathrm{RH}_{4}(\%)$ & $\omega_{3}$ & $\omega_{4}$ & $\left(\omega_{4}-\omega_{3}\right)$ & & \\
\hline \multirow{6}{*}{$\begin{array}{l}\infty \\
a \\
0 \\
i \\
11 \\
>\end{array}$} & (begin) & 28.8 & 48.0 & 69.3 & 11.3 & 0.012 & 0.022 & 0.010 & \multirow{6}{*}{20.7} & 20.7 \\
\hline & 10 & 29.5 & 48.0 & 45.8 & 42.4 & 0.012 & 0.027 & 0.015 & & 19.8 \\
\hline & 20 & 29.7 & 49.0 & 46.0 & 45.8 & 0.013 & 0.030 & 0.017 & & 18.9 \\
\hline & 30 & 29.9 & 50.0 & 47.3 & 42.0 & 0.013 & 0.029 & 0.016 & & 18.0 \\
\hline & 40 & 30.1 & 51.1 & 48.0 & 41.7 & 0.014 & 0.030 & 0.016 & & 17.1 \\
\hline & (finish) 48 & 30.4 & 51.2 & 48.4 & 33.4 & 0.014 & 0.024 & 0.010 & & 16.4 \\
\hline \multirow{6}{*}{$\begin{array}{l}n \\
\Xi \\
n \\
n \\
11 \\
>\end{array}$} & (begin) & 27.6 & 46.1 & 57.5 & 16.1 & 0.011 & 0.018 & 0.007 & \multirow{6}{*}{20.7} & 20.7 \\
\hline & 10 & 28.5 & 46.2 & 44.1 & 46.3 & 0.011 & 0.027 & 0.016 & & 19.6 \\
\hline & 20 & 29.1 & 47.4 & 47.2 & 41.5 & 0.012 & 0.029 & 0.017 & & 18.5 \\
\hline & 30 & 29.6 & 48.3 & 49.6 & 36.2 & 0.013 & 0.028 & 0.016 & & 17.4 \\
\hline & 40 & 29.9 & 49.8 & 50.7 & 34.1 & 0.013 & 0.028 & 0.015 & & 16.3 \\
\hline & (finish) 48 & 30.1 & 50.0 & 51.9 & 33.4 & 0.013 & 0.029 & 0.016 & & 15.4 \\
\hline \multirow{6}{*}{$\begin{array}{l}\text { aे } \\
0 \\
\dot{0} \\
\text { II } \\
>\end{array}$} & (begin) & 27.6 & 47.0 & 69.6 & 10.6 & 0.011 & 0.021 & 0.010 & \multirow{6}{*}{20.6} & 20.6 \\
\hline & 10 & 28.4 & 47.8 & 48.9 & 34.8 & 0.012 & 0.026 & 0.014 & & 19.3 \\
\hline & 20 & 29.0 & 49.7 & 53.5 & 28.9 & 0.012 & 0.027 & 0.015 & & 18.1 \\
\hline & 30 & 29.5 & 50.8 & 55.8 & 27.6 & 0.013 & 0.029 & 0.016 & & 16.9 \\
\hline & 40 & 29.8 & 52.3 & 57.3 & 25.6 & 0.014 & 0.029 & 0.015 & & 15.6 \\
\hline & (finish) 43 & 29.9 & 52.9 & 57.2 & 24.7 & 0.014 & 0.028 & 0.014 & & 15.3 \\
\hline
\end{tabular}

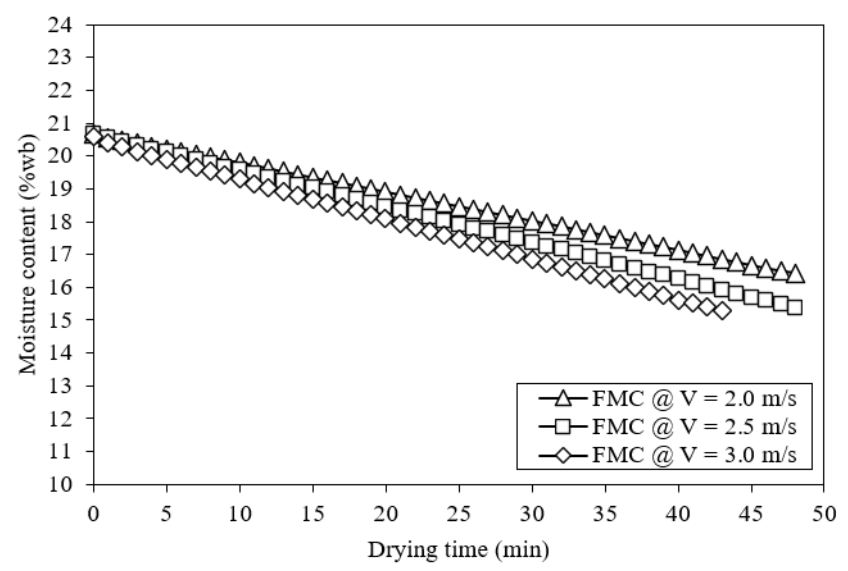

Fig. 8. The estimate final moisture content

C. Comparison between moisture detector with estimation by the mass balance method

Acceding to the experiment condition, the velocity of hot air flow was adjusted in three-levels, for a study of the estimation of moisture reduced in the drying process. As a result, amongst the beginning and the completion of the drying process, the user took a grain sample out of the drying process, then measured moisture by using the moisture (MC) detector, a grain sample was taken five times to measure the moisture, by using the average value, the standard deviation in consideration as shown in Fig. 9 and Table IV represents the comparison of FMC value between FMC from a moisture detector with the estimated value, the result shows that the FMC from the estimated value could be predicted the FMC with an average error of 4.3 percentage.

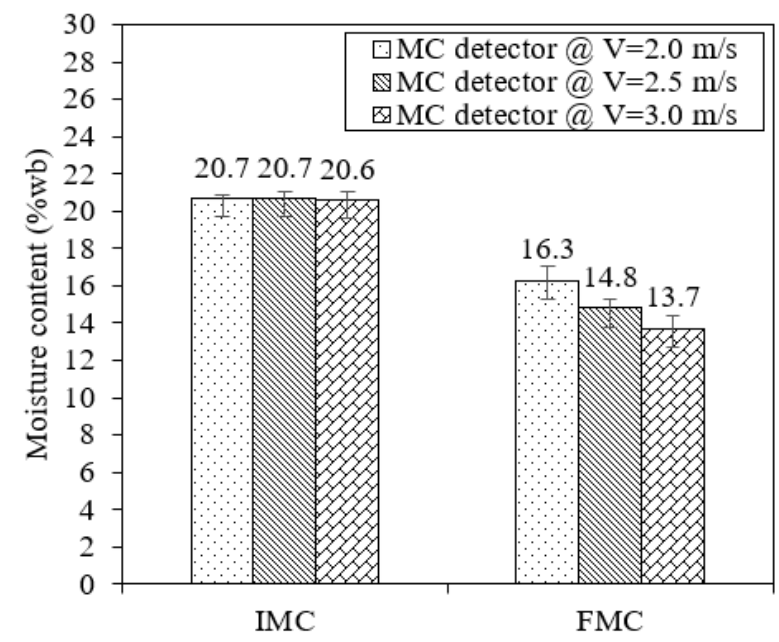

Fig. 9. A moisture detector (Riceter F512)

Besides, the drying process also has promoted the farmer, value-added for trading at rice mills, according to the DIT of Thailand as previously shown in Table I. 
TABLE V FINAL MOISTURE CONTENT BY MASS BALANCE

\begin{tabular}{|c|c|c|c|c|c|c|}
\hline \multicolumn{2}{|c|}{ Drying condition } & \multicolumn{4}{|c|}{ Final moisture content (FMC) } & \multirow{3}{*}{$\%$ error } \\
\hline \multirow{2}{*}{$\begin{array}{c}\text { hot air } \\
\text { temp. }\end{array}$} & \multirow{2}{*}{$\begin{array}{l}\text { velocity } \\
\text { air flow }\end{array}$} & \multicolumn{2}{|c|}{ grain detector } & \multicolumn{2}{|c|}{ estimated } & \\
\hline & & avg. & dev. & avg. & dev. & \\
\hline \multirow{3}{*}{130} & 2.0 & 16.3 & 0.8 & 15.3 & 0.5 & 6.1 \\
\hline & 2.5 & 14.8 & 0.5 & 13.9 & 0.6 & 6.1 \\
\hline & 3.0 & 13.7 & 0.7 & 13.8 & 0.4 & 0.7 \\
\hline \multicolumn{6}{|c|}{ average error } & 4.3 \\
\hline
\end{tabular}

\section{CONCLUSION}

The drying process has been processed that evaporates water from the material to a suitable level for trade or storage. Commonly, the moisture measurement must be taken a grain sample out of the drying process. As a result, the user knew the moisture level after the drying process has been carried out.

In this research, divided into two objectives the first objective, being that the temperature and relative humidity sensors were applied to read and record data, the second objective, the final moisture content (FMC) in the paddy drying process was calculated and estimated by using the mass balance method.

The first results showed that the temperature and relative humidity sensors can read and record the data values were successfully carried out, and the second results showed that the estimation by the mass balance method could be predicted by the FMC close to the moisture detector with an average error of 4.3 percentage when compared to a moisture detector, this method could be used with a dryer, which is an advantage, the user to know the moisture level during the dryer operates, without taking a grain sample out.

The system design features easy-to-obtain hardware and open-source Arduino software, making it accessible to use for the development of systems of their design and use, this adjustment makes the system more suitable for each expected application, such as the monitoring of dryer plants, control room, smart farm and smart dryer as well. However, subsequent improvements are subject to further research.

\section{ACKNOWLEDGMENT}

The authors would like to thank the head of the rice farming community at Suphan Buri province for their kind support and for sponsoring fresh paddy for this study.

\section{REFERENCES}

[1] O. Napasintuwong, "Rice Economy of Thailand," in "Agricultural and Resource Economics (ARE) Working Paper," Department of Agricultural and Resource Economics, Faculty of Economics, Kasetsart University, Bangkok, Thailand., 2019.

[2] C. Sowcharoensuk. "Rice Industry." https://www.krungsri.com/bank/getmedia/b37c70d6-3cf8-4add-8afe76f7dcceb402/IO_Rice_2016_EN.aspx (accessed Jan 26th, 2020).

[3] W. Jittanit, N. Saeteaw, and A. Charoenchaisri, "Industrial paddy drying and energy saving options," Journal of stored products research, vol. 46, no. 4, pp. 209-213, 2010.

[4] R. Lu, T. Siebenmorgen, T. Costello, and E. Fryar Jr, "Effect of rice moisture content at harvest on economic return," Applied engineering in agriculture, vol. 11, no. 5, pp. 685-690, 1995.

[5] D. B. Brooker, F. W. Bakker-Arkema, and C. W. Hall, Drying and storage of grains and oilseeds. Springer Science \& Business Media, 1992.
[6] M. Hossain, M. Awal, M. Ali, and M. Alam, "Use of moisture meter on the post-harvest loss reduction of rice," Progressive Agriculture, vol. 27, no. 4, pp. 511-516, 2016.

[7] K. Sookramoon and M. Khamwachirapithak, "Rice Grain Physical and Chemical analysis from Paddy Drying by Using a Solar Tunnel Dryer at Prathum Tani, Thailand," in MATEC Web of Conferences, 2016, vol. 68: EDP Sciences, p. 09001.

[8] C. Nimmol and S. Devahastin, "Evaluation of performance and energy consumption of an impinging stream dryer for paddy," Applied Thermal Engineering, vol. 30, no. 14-15, pp. 2204-2212, 2010.

[9] M. Yapha, P. Bunyawanichakul, and N. Hayinilah, "Coarse Rice Products by Must Flow Fluidization Techniques Diabetes Patents," International Journal at Science and Research) IJSR (, issn: 23197064, Vol. 3 issue 6, pp. 5-10, 2014.

[10] N. D. Pongsatit Sonpakdee, Churat Thararux, Tanate Chaichana, Rameshprabu Ramaraj, "Evaluate the efficacy of a must flow paddy dryer by using biomass for the small community," presented at the TriU International Joint Seminar and Symposium, 23-28 October, 2016.

[11] M. A. Billiris, T. J. Siebenmorgen, and G. L. Baltz, "Energy Use and Efficiency of Rice-Drying SystemsI. On-Farm Cross-Flow Dryer Measurements," Applied Engineering in Agriculture, vol. 30, no. 2, pp. 205-215, 2014.

[12] M. A. Billiris and T. J. Siebenmorgen, "Energy use and efficiency of rice-drying systems ii. Commercial, cross-flow dryer measurements," Applied Engineering in Agriculture, vol. 30, no. 2, pp. 217-226, 2014.

[13] M. Medojevic, A. Stojanovic, M. Lazarevic, I. Cosic, and N. Sremcev, "Development and testing of Arduino-based Relative Humidity and Dry Bulb Temperature data logger."

[14] Fandri Christanto, Rasional Sitepu, and A. Joewono, "Chips dryer applications using liquid petroleum gas power," ARPN Journal of Engineering and Applied Sciences, vol. 12, pp. 7070-7076, 2017.

[15] S. Ashfaq, M. Ahmad, and A. Munir, "Design, Development and Performance Evaluation of a Small-Scale Solar Assisted Paddy Dryer for on Farm Processing," Mehran University Research Journal of Engineering and Technology, vol. 35, no. 2, pp. 217-228, 2016.

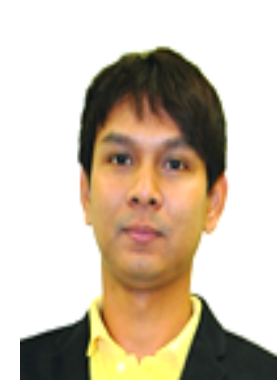

Surachai Hemhirun, the author's received the B. Eng. Degree in Mechanical Engineering from Rajamangala University of Technology Krungthep (RMUTK), Thailand in 2008 and M. Eng. Degree in Mechanical Engineering from King Mongkut's University of Technology Thonburi (KMUTT), Thailand in 2011. Currently, he is a lecturer at Rajamangala University of Technology Krungthep (RMUTK) and his research interest includes energy management for dryer, moisture measurement in grain, and automatic control systems.

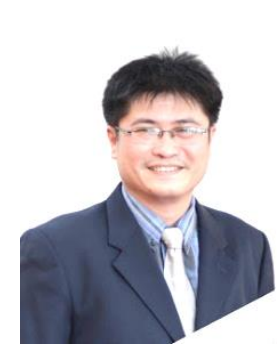

Pracha Bunyawanichakul, the author's received B. Eng. Degree in Agricultural Engineering from Kasetsart University (KU), Thailand in 1996, M. Eng. Degree in Agricultural Machinery and Management from Asin Institute of Technology (AIT), Thailand in 1998 and Ph. D. Degree in Mechanical Engineering from University of Tasmania, Australia in 2008. Currently, he is a lecturer at Srinakharinwirot University (SWU) and his research interest includes automatic control, applied engineering, and cross-flow dryer. 